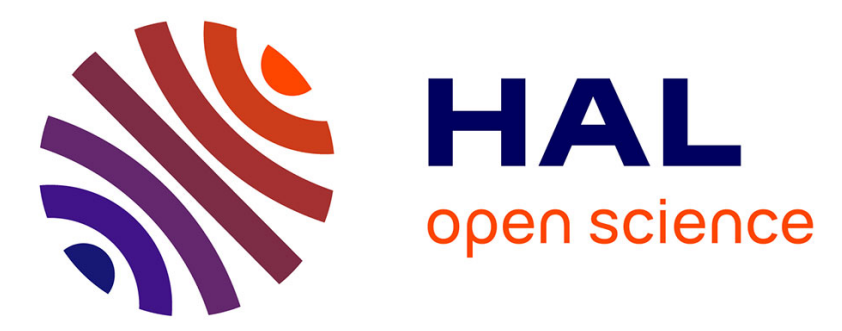

\title{
Increase in radon emission due to rock failure: an experimental study
}

Silvio Mollo, P. Tuccimei, Michael Heap, Sergio Vinciguerra, M. Soligo, M. Castelluccio, P. Scarlato, Donald B. Dingwell

\section{- To cite this version:}

Silvio Mollo, P. Tuccimei, Michael Heap, Sergio Vinciguerra, M. Soligo, et al.. Increase in radon emission due to rock failure: an experimental study. Geophysical Research Letters, 2011, 38, pp.L14304. 10.1029/2011GL047962 . hal-00724843

\section{HAL Id: hal-00724843 \\ https://hal.science/hal-00724843}

Submitted on 16 Jun 2021

HAL is a multi-disciplinary open access archive for the deposit and dissemination of scientific research documents, whether they are published or not. The documents may come from teaching and research institutions in France or abroad, or from public or private research centers.
L'archive ouverte pluridisciplinaire HAL, est destinée au dépôt et à la diffusion de documents scientifiques de niveau recherche, publiés ou non, émanant des établissements d'enseignement et de recherche français ou étrangers, des laboratoires publics ou privés.

$$
\text { Copyright }
$$




\title{
Increase in radon emission due to rock failure: An experimental study
}

\author{
S. Mollo, ${ }^{1}$ P. Tuccimei, ${ }^{2}$ M. J. Heap, ${ }^{3}$ S. Vinciguerra, ${ }^{1}$ M. Soligo, ${ }^{2}$ M. Castelluccio, ${ }^{2}$ \\ P. Scarlato, ${ }^{1}$ and D. B. Dingwell ${ }^{4}$ \\ Received 7 June 2011; accepted 13 June 2011; published 22 July 2011.
}

[1] Radon anomalies are commonly observed prior to dynamic failure in the crust and are interpreted as cracking of the medium, thus attracting considerable attention in understanding the precursory phenomena of earthquakes and volcanic activity. In this study we have compared the starting radon emissions from low porosity crystalline lava (phonolite) samples with those from damaged and failed samples. The damaged sample was loaded up to just beyond the end of the linear elastic phase, as evidenced by the output of AE energy, the increase in total porosity and a decrease in $\mathrm{P}$-wave and $\mathrm{S}$-wave velocity relative to the intact sample. Whereas, the failed sample showed deformation behaviour characteristically brittle with increasing values of $\mathrm{AE}$ output and porosity as the sample approached macroscopic failure. Radon measurements have evidenced that dilatational microcracking of deformed sample produced no significant variation in radon emanation with respect to the intact sample. In contrast, after macroscopic failure, radon emanation drastically increased. Therefore, major finding from this study is that, in the case of low porosity and relatively high strength crystalline lavas, the development of a macroscopic fracture provides new large exhaling surface resulting in a substantial increase in radon emission rate. Citation: Mollo, S., P. Tuccimei, M. J. Heap, S. Vinciguerra, M. Soligo, M. Castelluccio, P. Scarlato, and D. B. Dingwell (2011), Increase in radon emission due to rock failure: An experimental study, Geophys. Res. Lett., 38, L14304, doi:10.1029/2011GL047962.

\section{Introduction}

[2] The discovery that positive radon anomalies in soilgas and ground-water are commonly observed prior to earthquake rupture has attracted considerable attention in studies monitoring the precursory phenomena of earthquakes and volcanic activity [Cox et al., 1980; King et al., 1995; Linde and Sacks, 1998; Roeloffs, 1999; Trique et al., 1999]. However, this simplified picture has been contradicted by the lack of significant anomalies recorded before an earthquake [Kerr, 1978; King, 1981; Tsunogai and Wakita, 1995;

\footnotetext{
${ }^{1}$ Istituto Nazionale di Geofisica e Vulcanologia, Rome, Italy.

${ }^{2}$ Dipartimento di Scienze Geologiche, Università “Roma Tre," Rome, Italy.

${ }^{3}$ Laboratoire de Géophysique Expérimentale, UMR 7516, Institut de Physique de Globe de Strasbourg, CNRS, EOST, Université de Strasbourg, Strasbourg, France.

${ }^{4}$ Sektion Mineralogie, Petrologie and Geochemie, Department für Geo- und Umweltwissenschaften, University of Munich, Munich, Germany.

Copyright 2011 by the American Geophysical Union. 0094-8276/11/2011GL047962
}

Steinitz et al., 2003]. Further, sometimes negative anomalies are measured at the seismic source [Hauksson, 1981; Kuo et al., 2006], while contemporaneous positive anomalies are inexplicably recorded at monitoring stations located hundreds of kilometres away [Kerr, 1978, 1981]. Alternating increases and decreases have also been recorded prior to earthquake [Wakita et al., 1980; Igarashi et al., 1995]. Hence, in many cases, the simple measurement of radon emanation does not appear to be useful as a warning signal and several questions remain unresolved. Why are some earthquakes preceded by radon anomalies and others not? Why are radon anomalies recorded at scattered places far away from the site of the largest earthquake? If anomalies are site dependent, what factors may distinguish a good site from a bad one?

[3] Although numerous investigators have monitored field radon emanation from rocks under natural stress conditions, very few experimental studies have attempted to relate rock deformation with radon emission rate changes [Holub and Brady, 1981; Tuccimei et al., 2010]. Here we take the position that in order to fully unravel the relationship between deformation style, increasing damage and radon emission rate, experiments on contrasting rock types, representative of the wide variability we see in nature, must be undertaken and their results evaluated. To this end, here we present new experimental data for radon measurements performed on intact, damaged and failed samples of a low porosity (3.6\%) and relatively high strength crystalline lava (phonolite) from the Colli Albani volcanic district (Latium, Italy). Results are discussed in comparison with those recently reported for a loosely consolidated and highly porous (47\%) tuff from the same region [Tuccimei et al., 2010].

\section{Materials and Methods}

[4] The deformation experiments were performed on $53.7 \mathrm{~mm}$ diameter and $112 \mathrm{~mm}$ length cylindrical samples at a constant strain rate of $10^{-5} \mathrm{~s}^{-1}$ using a uniaxial press at the Technische Universität München (TUM), Munich, Germany. A first sample was loaded up to the failure, while a second was unloaded at a point just beyond the elastic phase, in order to impart a degree of irreversible microcrack damage. Output of acoustic emission (AE) energy was recorded by a PCI-2 MISTRAS AE system via a piezoelectric transducer strapped to the bottom loading anvil. The transducer has a high response band over the range from $100 \mathrm{kHz}-1 \mathrm{MHz}$ and data were recorded at a sampling rate of $10 \mathrm{MHz}$. The amplitude threshold, to exclude background noise, was kept at a constant $40 \mathrm{~dB}$.

[5] Rock physical properties and microstructural analysis were performed at the HP-HT Laboratory of the Istituto Nazionale di Geofisica e Vulcanologia (INGV), Roma, Italy. 


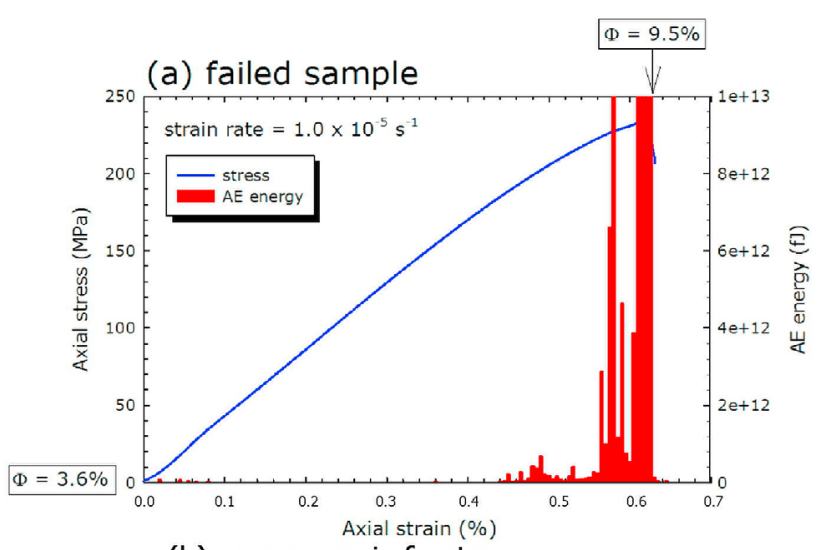

(b) macroscopic fracture
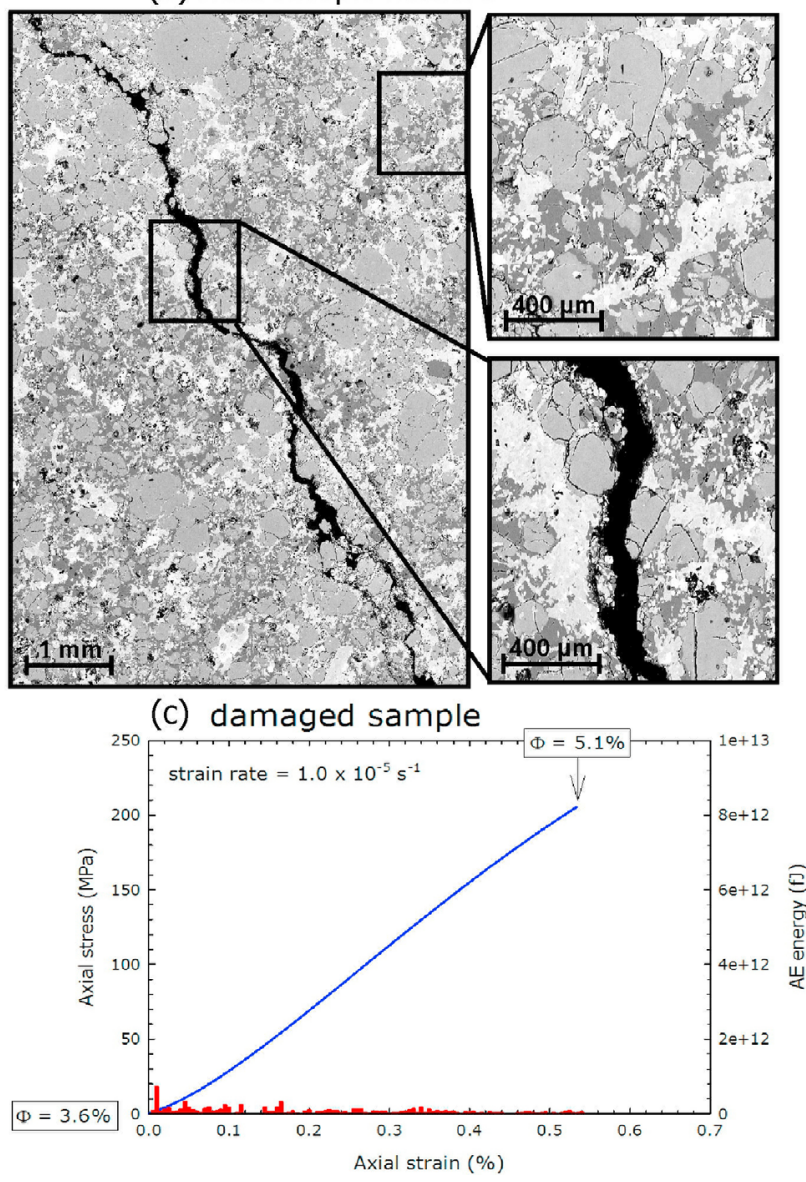

Figure 1. (a) Uniaxial stress-strain curves for lava samples taken to failure and (b) related FESEM map of the macroscopic fault. (c) Uniaxial stress-strain curves for lava samples taken to just beyond linear-elasticity. Changes in porosity and acoustic emission (AE) energy during the experiments are also shown on Figures $1 \mathrm{a}$ and $1 \mathrm{c}$.

Ultrasonic (P- and S-wave) velocities were measured on both intact and damaged samples using a high voltage (1000V) pulse generator and a Tektronix DPO4032 oscilloscope and two piezoelectric transducer crystals $(100 \mathrm{kHz}$ to $1 \mathrm{MHz}$ frequency). The porosity was determined using a helium pycnometer (AccuPyc II 1340). Measurements were firstly performed on the intact phonolite and then on compacted and failed samples by cutting three cubes $(2.5 \mathrm{~cm} / \mathrm{side})$ of material from the upper, central and lower portion of each sample in order to calculate a representative average porosity; in the case of the failed sample, cubes were cut in order to include the fracture surface. Microstructural analysis was carried out using a Jeol-JSM6500F Field Emission GunScanning Electron Microscope (FE-SEM).

[6] Radon analysis was performed at the "Environmental and Isotope Geochemistry" laboratory of "Roma Tre" University (Roma) using a continuous Radon Gas Monitor (RAD7, Durridge Company) equipped with a solid state alpha detector and a gas-drying unit to prevent moisture in the system. Samples were dried in an oven at $110^{\circ} \mathrm{C}$ for 24 hours and then placed inside an accumulation chamber kept at a constant temperature of $60^{\circ} \mathrm{C}$, with the aim to enhance radon atoms mobility and, thus gas exhalation from rocks [see also Tuccimei et al., 2009, 2011]. Radon emission rate was measured for intact, damaged and failed samples using the alpha spectrometer technique. Analyses were repeated six times in order to verify their reproducibility. The method allows the simultaneous measurements of radon and thoron using only the ${ }^{218} \mathrm{Po}$ peak for ${ }^{222} \mathrm{Rn}$ and ${ }^{216} \mathrm{Po}$ peak for ${ }^{220} \mathrm{Rn}$, obtaining a rapid equilibrium between polonium and radon nuclei. Since radon is essentially chemically inert, its transport behaviour in rocks is dominated by migration through connected pores and cracks (either preexisting or stress-induced). Radon has a short recoil length $\left(3 \times 10^{-8} \mathrm{~cm}\right)$ and, consequently, its lifetime diffusion distance is very limited. Therefore, only atoms produced at the surface of grains, trapped within the space of pores and/or adsorbed by the free inner surface of microcracks can be released from rock to the surrounding medium. Thus, the behaviour of radon emanation from a rock under a compressive stress is primarily dependent on the increase in the surface area within rock by whatever mechanism (e.g., changes in grain size, dilatant microcracking, compactive pore collapse, etc.).

\section{Results}

[7] Figure 1a shows the stress-strain curve of the first lava sample uniaxially loaded up to failure. Acoustic emission $(\mathrm{AE})$ output and total porosity $(\Phi)$ values are also shown, and are used as a proxy measure for microcrack damage. The failure occurred at $0.63 \%$ strain yielding an unconfined compressive strength (UCS) of $240 \mathrm{MPa}$ (Figure 1a). Deformation behaviour was seen to be characteristically brittle and we observed minor deviation from linear elastic deformation behaviour until immediately prior to failure, where a small degree of strain hardening was observed. AE output increased exponentially as the sample approached macroscopic failure (Figure 1a). The dilatant nature of the deformation was highlighted by an increase in total porosity from $3.6 \%$ in the intact sample to $9.5 \%$ in the failed sample (Figure 1a). Figure 1b reports an FESEM map of the macroscopic fault. The map shows that the macroscopic fracture formed parallel to the direction of the maximum principal stress (i.e., axial splitting) and that it represents a continuous, open conduit for the emanation of radon. We also observed that the deformation is, in general, fairly localised to the fault plane (see the insets of Figure 1b). Failure of this type has been previously observed for low porosity basalts [Heap et al., 2009, 2011]. 


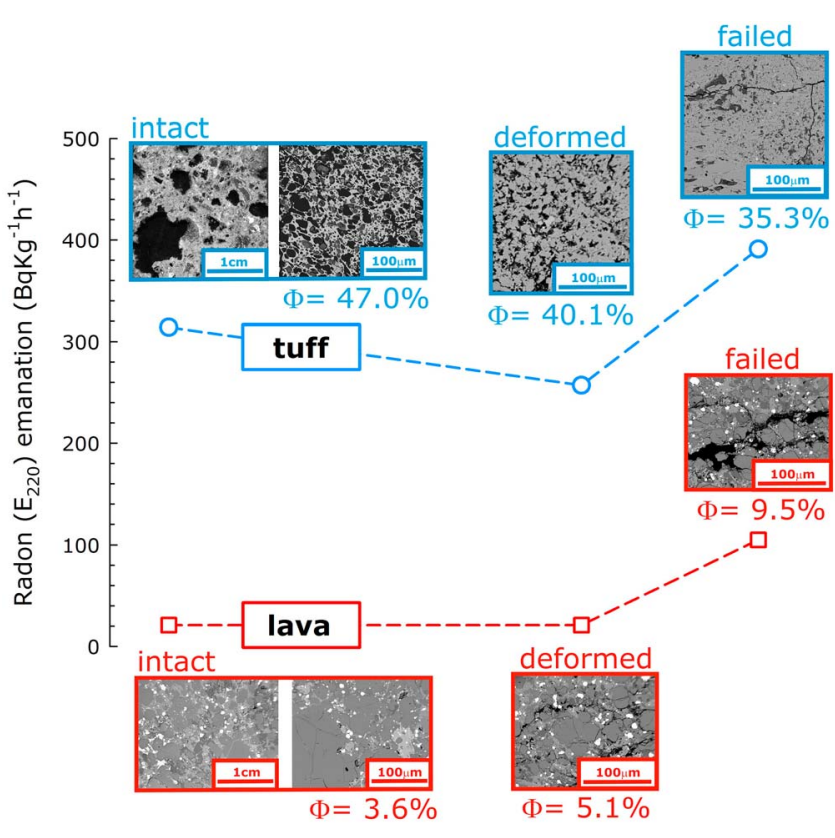

Figure 2. Comparison of ${ }^{220} \mathrm{Rn}$ emission, porosity data and microscopy analysis for the both tuff and lava samples.

[8] The second sample (hereinafter referred to as the 'damaged' sample) was loaded up to just beyond the end of the linear elastic phase $(0.53 \%$ of strain and $200 \mathrm{MPa})$, where it was unloaded at the same rate (Figure 1c). Although the rock did not macroscopically fail, it nevertheless contained a greater level of irreversible microcrack damage, as evidenced by the output of AE energy, the increase in total porosity (Figure 1c) and a decrease in $\mathrm{P}$-wave and S-wave velocity relative to the intact sample, from 5.51 to $5.09 \mathrm{~km} \mathrm{~s}^{-1}$ and from 3.84 to $3.39 \mathrm{~km} \mathrm{~s}^{-1}$, respectively. We must note that the output of AE energy at low strains was greater for this sample as compared to the sample taken to failure; however, we suggest that this merely reflects slight sample variability.

[9] The changes in radon emission rate of the phonolite samples are reported in Figure 2. The 'damaged' sample did not show any significant variation in radon emission rate $\left(21 \pm 6 \mathrm{~Bq} \mathrm{~kg}^{-1} \mathrm{~h}^{-1}\right)$ with respect to the intact sample $(21 \pm$ $\left.4 \mathrm{~Bq} \mathrm{~kg}^{-1} \mathrm{~h}^{-1}\right)$. This suggests that the level of microcrack damage imparted on the sample was not sufficient to drive changes in radon emanation (Figure 2). In contrast, postfailure, the phonolite sample showed a substantial increase in radon emission rate of $105 \pm 13 \mathrm{~Bq} \mathrm{~kg}^{-1} \mathrm{~h}^{-1}$ due to the occurrence of a large exhaling surface, in the form of a macroscopic fault (Figure 1b).

\section{Discussion}

[10] The major finding from this study is that, in the case of low porosity $(3.6 \%)$ and relatively high strength (UCS of $240 \mathrm{MPa}$ ) crystalline phonolite, the development of a macroscopic fracture (Figure 1b) provides new large exhaling surface that results in a substantial increase in radon emission rate (Figure 2). In contrast, radon emission rate measured from our 'damaged' sample did not show any significant variation with respect to that from the intact sample (Figure 2). Notably, previous studies on low porosity basalts have demonstrated that a significant portion of the damage required for failure is produced immediately prior to macroscopic sample rupture [Heap et al., 2011] and that significant changes in permeability are only seen after the formation of a large macroscopic fault [Fortin et al., 2011]. Consequently, it is likely that, although new emanation surfaces were created in the 'damaged' sample (see deformed lava in Figure 2), most are trapped within the material and the radon cannot escape.

[11] In Figure 2, we also report results from a previous study dealing with highly porous tuffs [Tuccimei et al., 2010]. These data show that, with respect to the intact sample, the deformation of tuff resulted in pervasive pore collapse that acted to reduce total porosity from $47.0 \%$ to $40.1 \%$ and thus decrease radon emission rate from $314 \pm 18$ to $257 \pm 19 \mathrm{~Bq} \mathrm{~kg}^{-1} \mathrm{~h}^{-1}$, respectively (Figure 2). Pore closure not only drastically reduced the rock surface area responsible for the radon emission, but is also likely to have significantly reduced permeability in highly porous rock [Zhu and Wong, 1997]. Upon failure, the tuff displayed a further decrease in porosity up to $35.3 \%$ (Figure 2); however, and similarly to that observed for the low porosity crystalline phonolite, the resulting macroscopic fault acted as a large exhaling surface that, consequently, resulted in a high radon emission rate of $391 \pm 27 \mathrm{~Bq} \mathrm{~kg}^{-1} \mathrm{~h}^{-1}$ (Figure 2).

[12] These data have important ramifications for the use of radon emissions as a predictive tool. Namely, they go some way in providing an explanation for the seemingly confusing array of radon anomalies seen prior to earthquakes in nature. Our experiments evidence that negative radon anomalies can be explained by the deformation of loosely consolidated and/or highly porous rocks (Figure 2); in contrast, a lack of significant variation in radon emanation can be due to the presence of low porosity crystalline materials. The latter suggests that the presence of low porosity materials could drastically reduce the prediction potential of radon monitoring. However, after macroscopic failure (e.g., in the form of an earthquake) has occurred, a significant increase in radon is observed. Thus, to use radon emissions successfully as a predictive tool, it is paramount to comprehend the underlying geology surrounding a fault or volcano within the range of all monitoring stations. The future application of high-resolution (spatial resolution of $10 \mathrm{~m}$ at a distance of $1 \mathrm{~km}$ ) cosmic-ray muon tomography in volcanic systems and fault zones may provide us with the needed capability of estimating regional porosity via density variations [Tanaka et al., 2007a, 2007b].

\section{Conclusions}

[13] We present new experimental data for radon measurements performed on intact, 'damaged' and failed samples of a low porosity and relatively high strength crystalline lava (phonolite). The following major conclusions can be drawn: (i) radon emission rate measured from a 'damaged' (deformed, but not taken to failure) lava sample will not show any significant variation relative to that measured from the intact sample; (ii) the development of a macroscopic fracture due to sample failure provides a new large exhaling surface leading to a substantial increase in radon emission rate.

[14] Our experimental investigation has the potential to shed light on several apparently contradictory signals recorded by radon monitoring stations near active faults and volcanoes. 
Previous radon measurements on highly porous tuffs have shown that radon emission rate from a 'damaged' tuff sample decreased relative to that from the intact sample; this was found to be due to pore closure. The data from the tuff samples differs with the observation from point (i) of this study because of the different rock characteristics, such as porosity and strength. However, after failure, radon emission rate from the failed tuff sample increased accounting for the formation of a large exhaling surface in agreement with our observation from point (ii).

[15] Further studies on the relationship between radon emissions and rock properties (e.g., porosity) are necessary for a realistic interpretation of radon signals from geochemical monitoring stations in seismic and volcanic areas.

[16] Acknowledgments. S. M. and S.V. was founded by FIRB MIUR "Development of innovative technologies for the environmental protection from natural events". M. J. Heap was funded by the German Federation of Materials Science and Engineering (BV MatWerk) and the German Research Foundation (DFG). D. B. Dingwell acknowledges support of a Research Professorship (LMUexcellent) of the Bundesexzellenzinitiative as well as ERC Advanced Grant "EVOKES". The authors would also like to thank Heiko Käsling (TUM) and Yan Lavallée (LMU) for experimental assistance.

\section{References}

Cox, E. M., E. K. Cuff, and M. D. Thomas (1980), Variations of ground radon concentrations with activity of Kilauea volcano, Hawaii, Nature, 288, 74-76, doi:10.1038/288074a0.

Fortin, J., S. Stanchits, S. Vinciguerra, and Y. Guéguen (2011), Influence of thermal and mechanical cracks on permeability and elastic wave velocities in a basalt from Mt. Etna volcano subjected to elevated pressure, Tectonophysics, 503, 60-74, doi:10.1016/j.tecto.2010.09.028.

Hauksson, E. (1981), Radon content of groundwater as an earthquake precursor: Evaluation of worldwide data and physical basis, J. Geophys. Res., 86, 9397-9410, doi:10.1029/JB086iB10p09397.

Heap, M. J., S. Vinciguerra, and P. G. Meredith (2009), The evolution of elastic moduli with increasing crack damage during cyclic stressing of a basalt from Mt. Etna volcano, Tectonophysics, 471, 153-160, doi:10.1016/j.tecto.2008.10.004.

Heap, M. J., P. Baud, P. G. Meredith, S. Vinciguerra, A. F. Bell, and I. G. Main (2011), Brittle creep in basalt and its application to time-dependent volcano deformation, Earth Planet. Sci. Lett., 307, 71-82, doi:10.1016/j. eps1.2011.04.035.

Holub, R. F., and B. T. Brady (1981), The effect of stress on radon emanation from rock, J. Geophys. Res., 86, 1776-1784, doi:10.1029/ JB086iB03p01776.

Igarashi, G., S. Saeki, N. Takahata, K. Sumikawa, S. Tasaka, Y. Sasaki, M. Takahashi, and Y. Sano (1995), Ground-water radon anomaly before the Kobe earthquake in Japan, Science, 269, 60-61, doi:10.1126/science. 269.5220.60.

Kerr, R. A. (1978), Earthquakes: Prediction proving elusive, Science, 200, 419-421, doi:10.1126/science.200.4340.419.

Kerr, R. A. (1981), The mountain is behaving itself-For now, Science, 212, 1258-1259, doi:10.1126/science.212.4500.1258-a.

King, C.-Y. (1981), Do radon anomalies predict earthquakes?, Nature, 293, 262, doi:10.1038/293262a0.
King, C.-Y., N. Koizumi, and Y. Kitagawa (1995), Hydrogeochemical anomalies and the 1995 Kobe earthquake, Science, 269, 38-39, doi:10.1126/ science.269.5220.38.

Kuo, T., K. Fan, H. Kuochen, Y. Han, H. Chu, and Y. Lee (2006), Anomalous decrease in groundwater radon before the Taiwan M 6.8 Chengkung earthquake, J. Environ. Radioact., 88, 101-106, doi:10.1016/j. jenvrad.2006.01.005.

Linde, A. T., and I. S. Sacks (1998), Triggering of volcanic eruptions, Nature, 395, 888-890, doi:10.1038/27650.

Roeloffs, E. (1999), Earth science: Radon and rock deformation, Nature, 399, 104-105, doi:10.1038/20072.

Steinitz, G., Z. B. Begin, and N. Gazit-Yaari (2003), Statistically significant relation between radon flux and weak earthquakes in the Dead Sea rift valley, Geology, 31, 505-508, doi:10.1130/0091-7613(2003) $031<0505:$ SSRBRF $>2.0 . \mathrm{CO} ; 2$

Tanaka, H. K. M., T. Nakano, S. Takahashi, J. Yoshida, and K. Niwa (2007a), Development of an emulsion imaging system for cosmic-ray muon radiography to explore the internal structure of a volcano, Mt. Asama, Nucl. Instrum. Methods Phys. Res., Sect A, 575, 489-497, doi:10.1016/j. nima.2007.02.104.

Tanaka, H. K. M., T. Nakano, S. Takahashi, J. Yoshida, M. Takeo, J. Oikawa, T. Ohminato, Y. Aoki, E. Koyama, H. Tsuji, and K. Niwa (2007b), High resolution imaging in the inhomogeneous crust with cosmic-ray muon radiography: The density structure below the volcanic crater floor of Mt. Asama, Japan, Earth Planet. Sci. Lett., 263, 104-113, doi:10.1016/j. eps1.2007.09.001.

Trique, M., P. Richon, F. Perrier, J. P. Avouac, and J. C. Sabroux (1999), Radon emanation and electric potential variations associated with transient deformation near reservoir lakes, Nature, 399, 137-141, doi:10.1038/20161.

Tsunogai, U., and H. Wakita (1995), Precursory chemical changes in ground water: Kobe earthquake, Japan, Science, 269, 61-63, doi:10.1126/science. 269.5220 .61 .

Tuccimei, P., M. Castelluccio, M. Soligo, and M. Moroni (2009), Radon exhalation rates of building materials: Experimental, Analytical protocol and classification criteria, in Building Materials: Properties, Performance and Applications, edited by D. N. Cornejo and J. L. Haro, pp. 259-273, Nova Sci., Hauppauge, N. Y.

Tuccimei, P., S. Mollo, S. Vinciguerra, M. Castelluccio, and M. Soligo (2010), Radon and thoron emission from lithophysae-rich tuff under increasing deformation: An experimental study, Geophys. Res. Lett., 37, L05305, doi:10.1029/2009GL042134.

Tuccimei, P., M. Castelluccio, S. Moretti, S. Mollo, S. Vinciguerra, and P. Scarlato (2011), Thermal enhancement of radon emission from geological materials. Implications for laboratory experiments on rocks under increasing deformation, in Horizons in Earth Science Research, vol. 4, edited by B. Veress and J. Szigethy, Nova Sci., Hauppauge, N. Y., in press

Wakita, H., Y. Nakamura, K. Notsu, M. Noguchi, and T. Asada (1980), Radon anomaly: A possible precursor of the 1978 Izu-Oshima-kinkai earthquake, Science, 207, 882-883, doi:10.1126/science.207.4433.882.

Zhu, W., and T. Wong (1997), The transition from brittle faulting to cataclastic flow in porous sandstones: Permeability evolution, J. Geophys. Res., 102, 3027-3041, doi:10.1029/96JB03282.

M. Castelluccio, M. Soligo, and P. Tuccimei, Dipartimento di Scienze Geologiche, Università "Roma Tre", Largo San Leonardo Murialdo 1, I-00146 Roma, Italy.

D. B. Dingwell, Sektion Mineralogie, Petrologie and Geochemie, Department für Geo- und Umweltwissenschaften, University of Munich, Theresienstr. 41, D-80333 Munich, Germany.

M. J. Heap, Laboratoire de Géophysique Expérimentale, UMR 7516 , Institut de Physique de Globe de Strasbourg, CNRS, EOST, Université de Strasbourg, 5 rue René Descartes, F-67084 Strasbourg CEDEX, France.

S. Mollo, P. Scarlato, and S. Vinciguerra, Istituto Nazionale di Geofisica e Vulcanologia, Via di Vigna Murata 605, I-00143 Roma, Italy. (mollo@ ingv.it) 